\title{
Bystanders of bullying: Social-cognitive and affective reactions to school bullying and cyberbullying
}

\author{
Rhea-Katharina Knauf', Heike Eschenbeck', \& Michael Hock² \\ ${ }^{1}$ Department of Educational Psychology and Health Psychology, University of Education Schwäbisch Gmünd, \\ Schwäbisch Gmünd Germany \\ ${ }^{2}$ Department of Psychology, University of Bamberg, Bamberg Germany
}

\begin{abstract}
The Bystander Intervention Model by Latané and Darley (1970) describes the stages necessary for a bystander to intervene in an emergency and can be used to explain bystander behavior in the case of bullying. Social-cognitive and affective reactions to bullying such as empathy with the victim, moral disengagement, feelings of responsibility, defender self-efficacy and outcome expectancy are supposed to determine whether a bystander passes through all stages of the intervention model and are thereby crucial for the behavioral response. These mental reactions were compared between school bullying and cyberbullying in a sample of 486 German students (56\% girls, age: $M$ $=12.95)$ from 28 classes with a newly developed questionnaire covering the five Social-Cognitive and Affective Reactions to Bullying (SCARB) for school context and cyber context separately. Confirmatory factor analysis showed an acceptable fit and internal consistency coefficients were acceptable to good. In line with our hypotheses, for cyberbullying as compared to school bullying students reported higher moral disengagement and lower feelings of responsibility and self-efficacy. However, no significant difference was found for empathy. The level of negative outcome expectations was lower for cyberbullying than for school bullying. Results confirm that the context of bullying matters for the social-cognitive and affective reactions of bystanders.
\end{abstract}

Keywords: School bullying; cyberbullying; bystander intervention model; empathy; moral disengagement; responsibility; self-efficacy; outcome expectations

\section{Introduction}

When a young person is bullied - be it in school or on the Internet - there are often witnesses who can either help the victim, participate in the bullying or remain passive (Pfetsch, 2016). The social-cognitive and affective reactions of the bystanders of bullying may help to explain different behavioral patterns and provide important suggestions for prevention programs. Some prevention programs already are designed to modify social-cognitive and affective reactions of the bystanders of bullying, such as empathy or the sense of responsibility (Polanin, Espelage, \& Pigott, 2012). Nonetheless, it remains unresolved whether social-cognitive and affective reactions are the same for cyberbullying as for school bullying or whether there are different focal points needed to prevent cyberbullying as opposed to preventing school bullying. Mental reactions associated with bullying and bystander behavior include empathy, moral disengagement, feelings of responsibility, self-efficacy, and outcome expectations. The aim of this study is to compare these five mental reactions to school bullying and to cyberbullying, and thereby in the long run contribute to an evidence-based optimization of prevention strategies. 


\section{Definition of Bullying and Cyberbullying}

Bullying is a subtype of aggression (Smith, Cowie, Olafsson, \& Liefooghe, 2002), characterized by regular occurrence and an asymmetric allocation of power (Olweus, 1993). The power of the bully can stem from physical strength, verbal dexterity or the relatively high position in the class hierarchy (cf. van Noorden, Haselager, Cillessen, \& Bukowski, 2015). These different sources of power imply different forms of bullying (van Noorden et al., 2015): Bullying can be physical (inflicting bodily harm or damaging property), directly verbal (insulting or stultifying the victim) or relational (excluding the victim or spreading rumors).

Digital media provide further means of bullying that can be classified as directly verbal, such as sending mean messages or posting insulting comments, or relational, such as excluding someone from social network groups or disseminating embarrassing videos. In this line, cyberbullying can easily be defined as "bullying using an electronic medium" (Dooley, Pyżalski, \& Cross, 2009, p. 182). Yet there are some intricacies to be considered when applying the definition criteria of school bullying to cyberbullying (cf. Dooley et al., 2009): First, repetition may not only result from multiple aggressive acts, but also can be due to manifold reception of a derogatory public content. Second, the power imbalance should not be understood as the bully's possession of power but rather as the victim's lack of power, which may arise from technical features. Victims of cyberbullying are unable to escape because negative online interactions can occur at any place and any time. Defamatory content can rapidly be distributed, may reach a vast audience and, once spread on the Internet, is not readily removed. Moreover, the anonymity of the perpetrator makes it difficult for the victims to defend themselves effectively and increases feelings of helplessness.

\section{Prevalence of School Bullying and Cyberbullying}

While it is unquestioned that bullying is a widespread problem, estimates of the prevalence rate vary widely due to different surveyed populations (e.g. grades, nations) and different applied methodologies (e.g. self- or peerreport, presented definition of bullying, cut-off criteria). Within the Health Behavior in School-Aged Children (HBSC) survey, self-report data on bullying and victimization were collected in representative samples from 40 countries (Craig et al., 2009): Prevalence rates of being involved in bullying as perpetrator, victim or both ranged from $8.6 \%$ to $45.2 \%$. On average $10.7 \%$ reported bullying others, $12.6 \%$ reported being bullied and $3.6 \%$ reported both.

A meta-analysis comparing school bullying and cyberbullying (Modecki, Minchin, Harbaugh, Guerra, \& Runions, 2014) reports mean prevalence rates of $35 \%$ for involvement in school bullying and $15 \%$ for involvement in cyberbullying. The pattern of lower cyberbullying rates was found in most of the studies, leading to the conclusion that cyberbullying is generally less frequent than school bullying. Nevertheless, the number of pupils affected (one in six) cannot be dismissed as negligible.

In addition to bullies and victims there is a considerable number of students witnessing the bullying incidents. Regarding school bullying, a large portion of pupils (63-73\%) report having observed peers being bullied (Oh \& Hazler, 2009; Rivers, Poteat, Noret, \& Ashurst, 2009). Studies focusing on cyberbullying found that $36 \%$ to $46 \%$ of adolescent participants had been witnesses of cyberbullying (DeSmet et al., 2016; Erreygers, Pabian, Vandebosch, \& Baillien, 2016; Holfeld \& Grabe, 2012; Olenik-Shemesh, Heiman, \& Eden, 2015). Hence, bullying-be it offline or online-is highly relevant for many students and teachers. A high potential of changing the course of bullying lies especially in the bystanders (Salmivalli, Voeten, \& Poskiparta, 2011).

\section{Bystander Behaviors in School Bullying and Cyberbullying}

In view of the relatively high rates of bullying witnesses, the question arises how bystanders react if they witness bullying. Salmivalli, Lagerspetz, Björkqvist, Österman, and Kaukiainen (1996) assumed that in school bullying all class members are somehow involved in the bullying process in different participant roles. Aside from bullies and victims there are assistants of the bully, who actively join in if someone else has started the bullying; reinforcers, who are coming around to watch and laugh about the bullying; outsiders, who stay out of the situation and defenders of the victim, who try to stop the bullying and to protect the victim. Regarding cyberbullying, bystanders may also adopt these roles, although their behavioral pattern might differ from the school context. Pfetsch (2016) points out the complexity of bystander roles in cyberspace because people can witness cyberbullying online (e.g., 
reading insulting posts in an online forum) as well as offline (being with the perpetrator or the victim while the attack takes place) and they can also react online as well as offline. Assistants may forward painful contents or back the bully by gathering embarrassing information about the victim. Reinforcers may show their approval by likes, emoticons, and comments or by laughing when it is brought up at school. Defenders may take the victim's side in online commentaries or confront the bully personally.

In a self-report study of Wachs (2012) the roles of bully (6\%), victim (5\%), assistant (4\%), defender (5\%), and passive bystander (11\%) also could be identified for cyberbullying. The overlap between school bullying and cyberbullying was high for the bystander roles: $66 \%$ of the cyberassistants, $60 \%$ of the cyberdefenders and $63 \%$ of the passive cyberbystanders had the same roles in the context of school bullying. In other studies, not explicitly referring to the Participant Role Approach, most participants (55\%) report doing nothing, almost as many (42-49\%) say they help and only few (5-10\%) admit to joining in or laughing about it (DeSmet et al., 2016; Erreygers et al., 2016; Olenik-Shemesh et al., 2015).

\section{Bystander Intervention Model}

To understand why witnesses of emergencies often do not intervene and to find ways to change their passivity, Latané and Darley (1970) developed a model of the intervention process, today known as the Bystander Intervention Model, postulating that five steps are necessary before a bystander intervenes: (1) A person must notice the event. (2) He or she needs to realize that it is an emergency and that there is need for action. (3) He or she has to take personal responsibility, (4) choose an appropriate option to intervene, and (5) finally, implement the intervention. This model is useful not only in explaining bystander behavior in the case of physical harm, but also in situations of social abuse like bullying. The five steps of the intervention process already have been successfully operationalized for bullying and sexual harassment (Nickerson, Aloe, Livingston, \& Feeley, 2014) and connected to the Participant Roles (Jenkins \& Nickerson, 2017): Defenders were more likely to pass through all five stages, whereas outsiders failed in the last step of implementing the intervention. Bullying and assisting were not associated to any of the five steps. Scrutinizing the measurements applied to track the bystander intervention model (DeSmet et al., 2016; Nickerson et al., 2014), one comes across social-cognitive and affective concepts that deserve more attention.

\section{Social-Cognitive and Affective Reactions in the Intervention Process}

Focusing on those who did report witnessing bullying and who consequently noticed the event, it is crucial to identify the underlying mental processes on the last four steps. Empathy is the ability to understand (cognitive empathy) and share (affective empathy) the emotions of another person (Jolliffe \& Farrington, 2011) and can be considered as a prerequisite to perceiving the victim's pain and therefore understanding the need to take some form of action. Moral disengagement, on the other hand, is likely to blur the need for action. Bandura and collegues (Bandura, Barbaranelli, Caprara, \& Pastorelli, 1996) described a set of mechanisms which disengage moral control from detrimental conduct: moral justification, euphemistic labeling, advantageous comparison, displacement of responsibility, diffusion of responsibility, distortion of the consequences, dehumanization and blaming the victim. Originally gathered to explain violent behaviors that are dissonant from personal moral principles, those mechanisms might also be useful for explaining passive or reinforcing behaviors in bullying situations. Bystanders who downplay the attacks and their effects on the victims, justify the bullying, and attribute the blame to the victims themselves, will presumably not see any need to change the situation.

Mechanisms of moral disengagement are also crucial for the feeling of responsibility. Bystanders applying moral disengagement strategies such as distancing themselves from the events and relying on others to solve the problem, will not feel responsible, whereas bystanders not using moral disengagement strategies are likely to experience moral self-sanctions such as pangs of conscience driving them to the next steps of the intervention process.

Relevant for the last two stages are knowledge, self-efficacy and outcome expectations (Bandura, 1977). Bystanders need to know the means of intervention, dare to accomplish them and be sure that these means will actually have the desired effect. Presumably, a particular obstacle is the apprehension of negative outcomes for the victim (worsening the situation) and for oneself (putting oneself at risk). 


\section{Social-Cognitive and Affective Correlates of Bullying and Bystander Behavior}

Regarding the social-cognitive and affective processes underlying bullying and bystander behavior, a large part of research has focused on empathy and moral disengagement. A systematic review of the association of empathy and involvement in bullying (van Noorden et al., 2015) came to the conclusion, that pro-bullying behavior (bullying, assisting and reinforcing) comes along with low empathy, whereas for defending the opposite is true. Heterogeneous findings emerged for the uninvolved. A meta-analysis on moral disengagement and aggressive behavior among children and adolescents (Gini, Pozzoli, \& Hymel, 2014) supports moral disengagement as a meaningful correlate of aggressive behavior in general as well as specifically bullying and cyberbullying. In the context of school bullying, moral disengagement is also linked to pro-bullying bystander behavior (assisting and reinforcing) and negatively related to defender behavior (Thornberg \& Jungert, 2013; Thornberg, Wänström, Hong, \& Espelage, 2017). Moreover, mechanisms of moral disengagement lower the preparedness to intervene in cyberbullying (DeSmet et al., 2014; DeSmet et al., 2016). Inconsistent findings exist regarding the association between moral disengagement and passive bystander behavior (Thornberg et al., 2017; Thornberg \& Jungert, 2013), which might be due to the fact that passive bystanders are an inhomogeneous group (cf. Obermann, 2011).

A lack of feeling of responsibility is sometimes investigated as one aspect of moral disengagement (displacement/diffusion of responsibility) and thereby negatively associated with defending (Thornberg \& Jungert, 2014) or the intention to show positive bystander behavior (DeSmet et al., 2016). Other studies investigating the sense of responsibility as a separate variable found a positive association with defending (Pozzoli \& Gini, 2010) and the intention to intervene (Obermaier, Fawzi, \& Koch, 2016). Moreover, the belief of bystanders that it is not their business to help is a common reason not to intervene in school bullying or cyberbullying (Olenik-Shemesh et al., 2015; Slee, 1994).

Social self-efficacy and specifically defender self-efficacy differentiates between defenders and passive bystanders (Gini, Albiero, Benelli, \& Altoè, 2008; Machackova, Dedkova, \& Mezulanikova, 2015; Pöyhönen, Juvonen, \& Salmivalli, 2012; Thornberg et al., 2017; Thornberg \& Jungert, 2013). Furthermore, positive outcome expectations such as stopping the bullying or making the victim feel better were positively related to defending and negatively related to reinforcing, whereas passivity was related to conflicting expectations and values (Pöyhönen et al., 2012). Negative outcome expectations such as fear of getting bullied are often reported as a reason for not defending the victim (Shultz, Heilman, \& Hart, 2014; Slee, 1994; van Cleemput, Vandebosch, \& Pabian, 2014).

The state of research clearly supports the relevance of empathy, moral disengagement, feelings of responsibility, self-efficacy and outcome expectancy for bystander behaviors in bullying situations. Less is known, however, about possible differences between school bullying and cyberbullying regarding these social-cognitive and affective reactions.

\section{Differences between School Bullying and Cyberbullying}

Technical aspects of cyberspace not only change the power relationship between perpetrator and victim as outlined above, but also the way bystanders perceive the incident. Online disinhibition and deindividuation have been adduced to explain cyberbullying (Lowry, Zhang, Wang, \& Siponen, 2016) and may also foster undesirable bystander behaviors such as assisting, reinforcing or remaining passive. Online interactions are characterized by physical distance, paucity of non-verbal cues, and sometimes anonymity, all of which may disinhibit anti-social behaviors (Suler, 2004). Social-cognitive and affective processes may mediate the online disinhibition effect: To be far away from the victim and not to see the victim's hurt is likely to impede empathy (Slonje \& Smith, 2008) and facilitate moral disengagement (Runions \& Bak, 2015). The invisibility of oneself, the asynchrony of online communication and the existence of many other witnesses will further decrease feelings of responsibility and thereby promote passivity. The potentially vast online audience as well as the powerful position of the cyberbully may additionally weaken self-efficacy and increase negative outcome expectations. To the best of our knowledge, no study thus far has directly compared these social-cognitive and affective reactions of bystanders of bullying between school and cyberspace. 


\section{Goal and Hypotheses of the Present Study}

Due to particular features of online interaction such as physical distance, lack of emotional cues and asynchronicity of communication as well as the powerful position of the cyberbully and the potentially vast online audience, we hypothesized that differences in the social-cognitive and affective reactions to bullying would emerge between the school context and the cyber context:

1. Empathy is assumed to be weaker in response to cyberbullying than in response to school bullying.

2. Moral disengagement is assumed to be more pronounced in the context of cyberbullying than in the context of school bullying.

3. Feelings of responsibility are assumed to be weaker in the context of cyberbullying than in the context of school bullying.

4. Self-efficacy for defending is assumed to be weaker in the case of cyberbullying than in the case of school bullying.

5. Negative outcome expectations of defending (apprehension of negative consequences) is assumed to be stronger for cyberbullying than for school bullying.

Associations with gender and age are documented for some of these variables like empathy and moral disengagement. Girls report higher levels of empathy and lower levels of moral disengagement than boys do (Paciello, Fida, Tramontano, Lupinetti, \& Caprara, 2008; van Cleemput et al., 2014). Moreover, girls are more likely to defend the victim and less likely to reinforce the bully (Pöyhönen et al., 2012; Thornberg et al., 2017). Age is negatively associated with both empathy and moral disengagement (Paciello et al., 2008; van Cleemput et al., 2014). Furthermore, older students are more likely to join in or reinforce the bullying, more likely to do nothing and less likely to help the victim than younger ones (Pöyhönen et al., 2012; van Cleemput et al., 2014). We therefore included gender and age as covariates in the regression models.

\section{Method}

\section{Participant Group}

Data were collected in 28 classes (Grades 6 and 8) from 10 different schools (mostly middle schools and common schools). The participation rate was $75 \%$ resulting in a sample of 486 students. Primary causes for not participating was unavailable parental consent (18.5\%) or absence of the student on the date of data collection (5.3\%). Seven students deliberately decided not to participate (1.1\%). The sample consisted of $44 \%$ boys and $56 \%$ girls; $35.8 \%$ of the participants had a migration background (mostly Turkey, Russia, and Kazakhstan). The age range reached from 10 to 16 years $(M=12.95 ; S D=1.29)$.

Of those participating, $67.5 \%$ reported having witnessed school bullying and $52.5 \%$ reported having witnessed cyberbullying. It has to be noted that for both types of bullying approximately one additional third of the participants was not entirely sure whether they had witnessed bullying. Only 3.9\% indicated they had never witnessed school bullying and $17.7 \%$ had never witnessed cyberbullying. Most of the participants had their own smartphone (98.6\%) and used the Internet on a daily basis (80.7\%).

\section{Data Collection}

Data collection took place in July 2017 in German school classes within one lesson by trained survey managers. The survey managers contacted schools via a cover letter that contained basic information about the study. In schools willing to participate, detailed information letters were sent to the parents to inform them about the topic of the survey as well as issues of anonymity, voluntariness, and data storage. Parents were asked to give their consent. On the day of data collection, the students were likewise informed. Only those with parental consent and who themselves agreed to participate took part in the study. Before filling in the questionnaire, a definition of bullying was read aloud; this was also printed on the first page of the questionnaire. At the end of the session, the participants were referred to contact persons at school and to options of anonymous consultancy in case of 
bullying. The study was conducted according to the ethical guidelines of the Deutsche Gesellschaft für Psychologie (German Psychological Association). The Research Ethics Committee of the University of Education Schwäbisch Gmünd approved the project.

\section{Statistical Procedure}

Analyses were conducted in R (2018) with the packages lavaan (Rosseel, 2012) for confirmatory factor analyses and multilevel (Bliese, 2016) to obtain information about the intraclass correlations (ICC). Because of augmented design effects for some scales (max. 2.59), estimated from the ICC (Maas \& Hox, 2005), random intercept models were calculated accounting for the variance between different classrooms and different individuals. We used the R-packages Ime4 (Bates, Maechler, Bolker, \& Walker, 2015) for multilevel regression and ImerTest (Kuznetsova, Brockhoff, \& Christensen, 2017) for significance testing. Regressions were based on linear (Gaussian) models.

\section{Measures}

A newly developed paper and pencil questionnaire was used to assess the students' bystander experiences and their Social-Cognitive and Affective Reactions to Bullying (SCARB). At first, an overall definition of bullying was given, using the German term "Schikanieren"1. Demographic information about age, gender and migrant background were obtained next. The main questionnaire consists of two parts: one about school bullying and one about cyberbullying. At the beginning of each section, the respective type of bullying was explained and examples were given orally and in written form. This explication was followed by questions about bystander experiences. For example, students were asked whether they had ever witnessed this type of bullying, how they had witnessed it, and who was bullied-at school and in cyberspace respectively. Answering these questions prompted the participants to reflect upon the bullying incidents and thereby ensured validity of the answers to the ensuing queries about their social-cognitive and affective reactions to bullying. Each part of the SCARB originally covered 44 corresponding items, all starting with the wording "When I notice someone being bullied at school" or "via digital media" respectively. Participants indicated how often (never $=0$, sometimes $=1$, mostly $=2$, always $=3$ ) they reacted in a certain way. The order of the two parts (school and cyber) was counterbalanced across class rooms, that is, participants of 16 class rooms were administered the questionnaire about school bullying first and the participants of the remaining 12 class rooms completed the questionnaire about cyberbullying first.

\section{Scales of the SCARB}

The collection of items was theory-driven and was aimed to cover the five introduced concepts: empathy, moral disengagement, feeling of responsibility, defender self-efficacy, and negative outcome expectations. With the objective of developing an efficient instrument, 24 items were selected based on observations during data collection (difficulties in understanding), item screening (distribution parameters and missing data), first exploratory factor analyses and theoretical considerations. We made sure that different aspects of empathy (perspective taking, affective empathy, and empathic concern) as well as moral disengagement (downplaying, justification, blaming the victim, and displacement/ diffusion of responsibility) were covered. To examine assignment of the items to the scales, we carried out confirmatory factor analyses based on the within-group covariances of school bullying items and cyberbullying items. For analyzing the data, maximum likelihood estimation with robust (Satorra-Bentler scaled) test statistics and robust fit indices were used. Corresponding to the postulated structure of the SCARB, five-factor models with an independent cluster structure, in which each item loads on only one factor (McDonald, 1999), were specified. Covariances between the five factors were allowed. Judged by approximate fit indices, both models yielded an acceptable fit. For school bullying $(n=464$ complete data sets) the fit indices were $\chi^{2}(242)=444.26, p<.001 ; \mathrm{CFI}=.941 ; \mathrm{RMSEA}=.046,90 \% \mathrm{Cl}[.039, .053]$ and SRMR $=.051$. For cyberbullying $\left(n=454\right.$ complete data sets) the fit indices were $\chi^{2}(242)=407.13, p<.001 ; \mathrm{CFI}=$ .949 ; RMSEA $=.042,90 \% \mathrm{Cl}[.035, .049]$ and SRMR $=.050$. All items showed salient positive loadings on their factor: Loadings varied between .41 and .81 for school bullying and .38 and .80 for cyberbullying. See tables A1 and A2 in the appendix for detailed information on the item wording, the item statistics ( $M, S D$, and factor loadings) and the correlations between the factors. Scale scores were calculated as means of the corresponding items, if there were at least three values available. Table 1 gives an overview over the five scales and their internal consistencies. 


\begin{tabular}{|c|c|c|c|c|c|}
\hline \multirow[b]{2}{*}{ Scale (number of items) } & \multicolumn{2}{|c|}{$\begin{array}{l}\text { Cronbach's Alpha } \\
\text { (McDonald's Omega) }\end{array}$} & \multicolumn{2}{|r|}{$\begin{array}{r}M \\
(S D)\end{array}$} & \multirow[t]{2}{*}{$r_{S B}, \mathrm{CB}$} \\
\hline & SB & CB & SB & CB & \\
\hline \multirow[t]{2}{*}{ Empathy (6) } & .86 & .87 & 1.64 & 1.60 & $.79 * \star$ \\
\hline & $(.87)$ & $(.87)$ & $(0.76)$ & $(0.77)$ & \\
\hline \multirow[t]{2}{*}{ Moral Disengagement (9) } & .80 & .80 & 0.89 & 0.94 & $.70 * \star$ \\
\hline & $(.80)$ & $(.80)$ & $(0.52)$ & $(0.52)$ & \\
\hline \multirow[t]{2}{*}{ Responsibility (3) } & .79 & .79 & 1.30 & 1.22 & $.75^{\star \star}$ \\
\hline & $(.79)$ & $(.80)$ & $(0.83)$ & $(0.81)$ & \\
\hline \multirow[t]{2}{*}{ Defender Self-Efficacy (3) } & .77 & .71 & 1.44 & 1.38 & $.64^{\star \star}$ \\
\hline & $(.78)$ & $(.71)$ & $(0.74)$ & $(0.71)$ & \\
\hline Negative Outcome & .74 & .66 & 1.01 & 0.95 & $.69 * *$ \\
\hline Expectations (3) & $(.75)$ & $(.69)$ & $(0.80)$ & $(0.76)$ & \\
\hline
\end{tabular}

\section{Results}

Table 2 displays the results of the random intercept models for each of the five social-cognitive and affective reactions to bullying with type of bullying (school bullying vs. cyberbullying) as predictors and gender and age as covariates. In general, only a small portion of variability of the scores for social-cognitive and affective reactions was due to differences between classes, while most variability stemmed from differences between subjects, even after controlling for gender and age. Gender had a significant effect on all reactions but self-efficacy. Age was associated only with empathy and moral disengagement. The effect of the type of bullying, though less pronounced than the gender differences, was significant for all reactions but empathy. We tested for interactions between type of bullying and gender as well as type of bullying and age. No significant interactions emerged ( $p s$ $>$.112) and the main effects for the type of bullying did not change, which is why we report the less complex model. Moreover, we ran the analyses without participants who reported that they had never witnessed school bullying or cyberbullying (remaining sample $n=385$ ), which yielded the same pattern of results.

Table 2. Random Intercept Models for the Five Social-Cognitive and Affective Reactions to Bullying.

\begin{tabular}{|c|c|c|c|c|c|}
\hline Fixed Effects & $\begin{array}{r}\text { Empathy }^{a} \\
B(S E)\end{array}$ & $\begin{array}{l}M^{a} \\
B(S E)\end{array}$ & $\begin{array}{r}\text { Responsibility }^{b} \\
B(S E)\end{array}$ & $\begin{array}{r}\text { Self-Efficacy }^{b} \\
B(S E)\end{array}$ & $\begin{array}{l}\mathrm{NOE}^{a} \\
B(S E)\end{array}$ \\
\hline Intercept & $1.34(0.06)^{\star \star \star}$ & $1.09(0.04)^{\star \star \star}$ & $1.11(0.06)^{\star \star \star}$ & $1.40(0.06)^{\star \star \star}$ & $0.87(0.06)^{\star \star \star}$ \\
\hline CB vs. SB & $-0.04(0.02)$ & $0.05(0.02)^{\star \star}$ & $-0.08(0.03)^{\star \star}$ & $-0.06(0.03)^{\star}$ & $-0.07(0.03)^{\star}$ \\
\hline Gender & $0.53(0.06)^{\star \star *}$ & $-0.35(0.04)^{\star \star *}$ & $0.33(0.07)^{\star \star \star}$ & $0.03(0.06)$ & $0.26(0.06)^{\star \star *}$ \\
\hline Age & $-0.07(0.03)^{\star}$ & $0.05(0.02)^{\star}$ & $-0.04(0.03)$ & $-0.01(0.03)$ & $-0.06(0.03)$ \\
\hline Random Effects & $\sigma^{2}(S D)$ & $\sigma^{2}(S D)$ & $\sigma^{2}(S D)$ & $\sigma^{2}(S D)$ & $\sigma^{2}(S D)$ \\
\hline Subject & $0.37(0.61)$ & $0.14(0.37)$ & $0.45(0.67)$ & $0.31(0.56)$ & $0.39(0.63)$ \\
\hline Class & $0.02(0.15)$ & $0.02(0.13)$ & $0.04(0.19)$ & $0.04(0.20)$ & $0.01(0.12)$ \\
\hline Residual & $0.12(0.34)$ & $0.08(0.27)$ & $0.16(0.40)$ & $0.18(0.42)$ & $0.18(0.42)$ \\
\hline
\end{tabular}

Note: Type of bullying is dummy coded with school bullying $(\mathrm{SB})=0$ and cyberbullying $(\mathrm{CB})=1$; gender is dummy coded with boys $=0$ and girls = 1; age is grand-mean centered; $\mathrm{MD}=$ moral disengagement; $\mathrm{NOE}=$ negative outcome expectations.

${ }^{\mathrm{a}} n=480 .{ }^{\mathrm{b}} n=479$.

${ }^{*} p<.05 .{ }^{*} p<.01 . * * * p<.001$. 
Empathy. There was no significant difference in empathy scores between school bullying and cyberbullying, $t(479)=1.89, p=.060$. Girls reported stronger empathy than boys, $t(474)=8.73, p<.001$. Age was negatively related to empathy, $t(51)=2.34, p=.023$.

Moral disengagement. Scores of moral disengagement were higher for cyberbullying compared to school bullying, $t(479)=2.78, p=.006$. Girls reported lower moral disengagement than boys, $t(470)=9.00, p<.001$. Age was positively related to moral disengagement, $t(63)=2.42, p=.018$.

Responsibility. A lower sense of responsibility was reported for cyberbullying compared to school bullying, $t(471)=2.92, p=.004$. The sense of responsibility was more pronounced in girls than boys, $t(470)=4.80, p<.001$. No effect was found for age, $t(50)=1.17, p=.246$.

Self-efficacy. Self-efficacy scores were lower for cyberbullying compared to school bullying, $t(473)=2.03, p=$ .043. No effect emerged for gender, $t(467)=0.44, p=.658$, or age, $t(55)=0.31, p=.761$.

Negative outcome expectations. In the context of cyberbullying less negative outcome expectations were reported, $t(474)=2.53, p=.012$. Negative outcome expectations were higher among girls than among boys, $t(476)=4.00, p<.001$. There was no significant effect of age, $t(47)=1.91, p=.062$.

\section{Discussion}

The comparison between school bullying and cyberbullying regarding the social-cognitive and affective reactions of bystanders revealed important differences between these two contexts. In line with our hypotheses, in the context of cyberbullying moral disengagement was stronger, whereas feelings of responsibility and defender selfefficacy were weaker. Technical aspects of the cyberspace may promote mechanisms of moral disengagement such as downplaying the incidents, justifying the attacks and blaming the victim as well as displacing the responsibility. In cyberspace, students witness bullying without directly catching the victim's emotional response and sometimes even without knowing the victim personally. This makes it difficult to assess the situation correctly and decide whether it is bullying or whether it is just teasing or something the target of the attack can handle him- or herself. Moreover, in cases of cyberbullying witnesses may have less contextual information. Sometimes they only know the unfavorable exposure of the victim through the bullies, which prompts the recipients to blame the victim and at times even makes the attacks seem justified. The displacement of responsibility may be facilitated and feelings of responsibility may be weakened in cyberspace due to physical distance from the victim, the delayed noticing of the event, one's own invisibility and the potential existence of many other witnesses.

Unexpectedly, however, there was no difference between school context and cyberspace in empathic reactions. This might be due to the fact that the measurement included items targeting both cognitive and affective aspects of empathy. It is possible that only affective empathy, which heavily relies on emotional cues in direct contact (Barlińska, Szuster, \& Winiewski, 2013), is impaired in cyberspace, whereas the level of cognitive empathy is the same for school bullying and cyberbullying. Contrary to this assumption, however, Carrier, Spradlin, Bunce, and Rosen (2015) found that cognitive empathy was impacted more by the virtual context than was affective empathy. Another explanation might be that empathy is less context-dependent than the other reactions and more determined by personal traits.

Furthermore, the power of the cyberbully was expected to lower defender self-efficacy and to heighten negative outcome expectations. Only the former assumption was confirmed by our data. Interestingly, negative outcome expectations were even lower in the context of cyberbullying. The physical distance and invisibility of the cyberbully as well as the opportunity of the witnesses to stay anonymous seem to reduce the fear of adverse consequences of intervening, which is in a way consistent with the assumption of online disinhibition (Suler, 2004).

Regarding gender comparisons, most differences were as expected: Girls reported more empathy and feelings of responsibility, whereas boys reported more moral disengagement. This is in line with previous findings on empathy (Eisenberg \& Lennon, 1983; van Noorden et al., 2015) and moral disengagement (Bandura et al., 1996; Thornberg \& Jungert, 2013), whereas until now no gender differences in the sense of responsibility for intervening in bullying has been found (Pozzoli \& Gini, 2010). The finding that girls reported mental reactions typical for 
defenders (empathy and feelings of responsibility) and boys reported mental reactions associated with bullying (moral disengagement) is also consistent with empirical evidence showing that girls act as defenders more often, whereas boys are more likely to show pro-bullying-behaviors (Salmivalli et al., 1996; Thornberg et al., 2017). That girls also reported more negative outcome expectations corresponds to the female proneness to anxiety (McLean \& Anderson, 2009) and is also in accordance with studies identifying more female than male outsiders (Salmivalli et al., 1996), though the state of research is heterogeneous in this respect (Thornberg et al., 2017). In contrast to a study that found higher defender self-efficacy in boys (Thornberg \& Jungert, 2013), no gender difference in defender self-efficacy was found in this study.

Age-related differences were observed for empathy and moral disengagement only. Empathy was lower in older students, which replicates the findings of van Clemput and colleagues (2014). Moral disengagement on the other hand was higher in older students, which is contrary to the findings of Paciello and colleagues (2008). This difference may be due to the fact that the present study specifically examined moral disengagement in bullying situations, whereas Paciello and colleagues (2008) investigated moral disengagement in general. Both lower levels of empathy and higher levels of moral disengagement in older students however fit the finding that older students are less prone to help and more prone to take part in bullying actions (Thornberg et al., 2017; van Cleemput et al., 2014).

\section{Strengths, Limitations and Further Research}

There is little research covering the social-cognitive and affective reactions of bystanders relevant for all steps of the intervention process and no research comparing those mental reactions between school bullying and cyberbullying. The present study provides a new questionnaire to assess five social-cognitive and affective reactions to bullying (SCARB) and delivers first results concerning the comparison of the two types of bullying addressed in this questionnaire. Although the findings are promising, there are some limitations to be noted. The practical relevance of the findings still needs to be examined. The sample was relatively small and not representative. However, the sample included different school types and the participation rate was high in the participating school classes. A cross validation of the measurement structure as well as a replication of the presented findings in a larger sample with a wider age range are desirable. To extend validity, future studies should take into account other factors possibly influencing the social-cognitive and affective reactions to bullying, such as the students experience with school bullying and cyberbullying (their participant roles) or their familiarity with digital media, and control for potential interactions.

Moreover, not all students had actually witnessed bullying. It is possible that those pupils who were not direct witnesses to bullying, referred to cases they had heard elsewhere when they completed the questionnaire. Besides, students were instructed to complete the questionnaire for instances where someone was treated nastily if they were not entirely sure that it was bullying. Findings therefore might in part reflect reactions to aggressive behavior in general and not exclusively bullying. However, the exclusion of those who reported that they had never witnessed bullying did not change the pattern of results. Future studies with a larger sample should examine whether there are differences between different ways of witnessing bullying (e.g. being present vs. getting told about it by someone) as well as between pupils who are sure that they have witnessed bullying and those who are unsure. Furthermore, the questionnaire might be adapted to target social-cognitive and affective reactions to general aggression at school or in cyberspace.

An important long-term objective is the verification of the association between the scales of the SCARB and the steps of the Bystander Intervention Model as well as the participant roles. In this regard, a comparison between the contexts would make sense. Firstly, it should be examined, whether the social-cognitive and affective reactions are equally important in the context of school bullying and cyberbullying to move from one step to the next within the Bystander Intervention Model. Secondly, it would be promising to examine whether the link between mental reaction and role is the same for both forms of bullying or if some connections are stronger in one context. In the course of this, cross-context effects should also be considered. Longitudinal research is especially needed to determine causal relationships. It is commonly assumed, that mental reactions influence behavioral responses. On the other hand, a reverse causal direction is also conceivable: The participant role might change the ways in which a bullying situation is perceived. Longitudinal research may clarify how anti-bullying programs can modify mental reactions and whether these changes mediate the effects on behavior. Finally, more differentiated 
research on the relevance of different facets of empathy and moral disengagement will be helpful to design suitable preventive exercises.

In this study the bystanders' reactions to school bullying and to cyberbullying were compared. Apart from the type of bullying, other characteristics of the bullying situation such as the perceived number of other bystanders or the relationship of the witness to the victim are relevant for bystander behavior (Machackova et al., 2015). The way bullying is noticed (e.g. seeing it online vs. being with the perpetrator vs. being told by the victim) as well as circumstances of the witnessing (delayed vs. immediate, physical distance vs. proximity to the bully, being visible vs. invisible for perpetrators and other witnesses) might also be important. These aspects will probably moderate the effect of school bullying versus cyberbullying on social-cognitive and affective reactions and are worth to be investigated in future studies.

\section{Conclusion and Practical Implications}

The aim of this study was to detect differences in the social-cognitive and affective reactions of bystanders to school bullying and to cyberbullying. Moral disengagement, which is linked to bullying as well as assisting and reinforcing behaviors of bystanders (Gini et al., 2014; Thornberg \& Jungert, 2013), was more pronounced in the cyber context than in the context of school bullying. Feelings of responsibility on the other hand, which are associated with defending behavior (Pozzoli \& Gini, 2010), were less pronounced in cyberbullying. Furthermore, a low defender self-efficacy, which goes along with passive bystander behavior (Thornberg et al., 2017), was found for cyberbullying compared to school bullying. These findings indicate that bystanders may react less desirably in the context of cyberbullying than in the context of school bullying. Exceptions are empathy (no differences were found) and outcome expectancy (less negative expectations were found for cyberbullying).

Bystander behavior is known to influence the frequency of school bullying (Salmivalli et al., 2011) and buffer the effect of risk factors for victimization (Kärnä, Voeten, Poskiparta, \& Salmivalli, 2010). While standing up for the victim counteracts the bullying, reinforcing behavior such as watching, laughing or making comments contributes to worsening the situation. Even ignoring the bullying might be seen as tacit approval by the perpetrators (Salmivalli et al., 1996). Therefore, it is a promising target for anti-bullying programs to mobilize bystanders. The differences between bystanders' mental reactions to school bullying and cyberbullying imply that prevention programs need to tackle these mental reactions in ways sensitive to different forms of bullying. In the context of cyberbullying it is particularly important to address believes that justify or downplay the attacks and to strengthen the sense of responsibility for a non-violent online interaction. Moreover, it is promising to work out specific strategies against different types of bullying to increase defender self-efficacy. In the context of school bullying it is especially important to discuss the risks of intervening and develop risk-free means of intervening. For cyberbullying students can be instructed how to take advantage of the technical features such as privacy settings that make them less vulnerable and means of documenting incidents. Obviously, prevention programs should cover as many social-cognitive and affective reactions of bystanders as possible. The findings of the present study, however, allow recommendations for the setting of priorities. The overlap between school and cyberbullying suggests extending school programs to include strategies against cyberbullying as well. Of course, parents and communities can also contribute by rising awareness and feelings of responsibility and providing points of contact.

Considering the importance of social media for adolescents (O'Keeffe \& Clarke-Pearson, 2011), it is vital to know more about the risks of online communication as well as the differences between online and offline interactions. This study attempts to contribute to a better understanding of bystanders' reactions to cyberbullying as well as school bullying, and seeks to find ways how responsible and supportive bystander behavior can be promoted.

\section{Notes}

1. The full definition translated into English was as follows: Bullying is when a student is repeatedly subjected to physical or psychological harm by fellow students over a longer period of time and he or she cannot defend himself or herself against it. It is not bullying when students argue or fight who are equally strong! 


\section{References}

Bandura, A. (1977). Self-efficacy: Toward a unifying theory of behavioral change. Psychological Review, 84, 191215.

Bandura, A., Barbaranelli, C., Caprara, G. V., \& Pastorelli, C. (1996). Mechanisms of moral disengagement in the exercise of moral agency. Journal of Personality and Social Psychology, 71, 364-374.

http://dx.doi.org/10.1037/0022-3514.71.2.364

Barlińska, J., Szuster, A., \& Winiewski, M. (2013). Cyberbullying among adolescent bystanders: Role of the communication medium, form of violence, and empathy. Journal of Community \& Applied Social Psychology, 23, 37-51. https://doi.org/10.1002/casp.2137

Bates, D., Maechler, M., Bolker, B., \& Walker, S. (2015). Fitting linear mixed-effects models using Ime4. Journal of Statistical Software, 67, 1-48. https://doaj.org/article/7f279483412348928f01507440b0360d

Bliese, P. (2016). multilevel: Multilevel Functions (R package version 2.6.). Retrieved from https://CRAN.Rproject.org/package=multilevel

Carrier, L. M., Spradlin, A., Bunce, J. P., \& Rosen, L. D. (2015). Virtual empathy: Positive and negative impacts of going online upon empathy in young adults. Computers in Human Behavior, 52, 39-48.

https://doi.org/10.1016/j.chb.2015.05.026

Craig, W., Harel-Fisch, Y., Fogel-Grinvald, H., Dostaler, S., Hetland, J., Simons-Morton, B., . . Pickett, W. (2009). A cross-national profile of bullying and victimization among adolescents in 40 countries. International journal of Public Health, 54, 216-224. https://doi.org/10.1007/s00038-009-5413-9

DeSmet, A., Bastiaensens, S., van Cleemput, K., Poels, K., Vandebosch, H., Cardon, G., \& Bourdeaudhuij, I. de. (2016). Deciding whether to look after them, to like it, or leave it: A multidimensional analysis of predictors of positive and negative bystander behavior in cyberbullying among adolescents. Computers in Human Behavior, 57, 398-415. https://doi.org/10.1016/j.chb.2015.12.051

DeSmet, A., Veldeman, C., Poels, K., Bastiaensens, S., van Cleemput, K., Vandebosch, H., \& De Bourdeaudhuij, I. (2014). Determinants of self-reported bystander behavior in cyberbullying incidents amongst adolescents.

Cyberpsychology, Behavior and Social Networking, 17, 207-215. https://doi.org/10.1089/cyber.2013.0027

Dooley, J. J., Pyżalski, J., \& Cross, D. (2009). Cyberbullying versus face-to-face bullying. Zeitschrift Für Psychologie, 217, 182-188. https://doi.org/10.1027/0044-3409.217.4.182

Eisenberg, N., \& Lennon, R. (1983). Sex differences in empathy and related capacities. Psychological Bulletin, 94, 100-131. https://doi.org/10.1037/0033-2909.94.1.100

Erreygers, S., Pabian, S., Vandebosch, H., \& Baillien, E. (2016). Helping behavior among adolescent bystanders of cyberbullying: The role of impulsivity. Learning and Individual Differences, 48, 61-67.

https://doi.org/10.1016/j.lindif.2016.03.003

Gini, G., Albiero, P., Benelli, B., \& Altoè, G. (2008). Determinants of adolescents' active defending and passive bystanding behavior in bullying. Journal of Adolescence, 31, 93-105.

https://doi.org/10.1016/j.adolescence.2007.05.002

Gini, G., Pozzoli, T., \& Hymel, S. (2014). Moral disengagement among children and youth: A meta-analytic review of links to aggressive behavior. Aggressive Behavior, 40, 56-68. https://doi.org/10.1002/ab.21502

Holfeld, B., \& Grabe, M. (2012). Middle school students' perceptions of and responses to cyber bullying. Journal of Educational Computing Research, 46, 395-413. https://doi.org/10.2190/EC.46.4.e 
Jenkins, L. N., \& Nickerson, A. B. (2017). Bullying participant roles and gender as predictors of bystander intervention. Aggressive Behavior, 43, 281-290. https://doi.org/10.1002/ab.21688

Jolliffe, D., \& Farrington, D. P. (2011). Is low empathy related to bullying after controlling for individual and social background variables? Journal of Adolescence, 34, 59-71. https://doi.org/10.1016/j.adolescence.2010.02.001

Kärnä, A., Voeten, M., Poskiparta, E., \& Salmivalli, C. (2010). Vulnerable children in varying classroom contexts: Bystanders' behaviors moderate the effects of risk factors on victimization. Merrill-Palmer Quarterly, 56, 261-282. https://doi.org/10.1353/mpq.0.0052

Kuznetsova, A., Brockhoff, P. B., \& Christensen, R. H. B. (2017). ImerTest package: Tests in linear mixed effects models. Journal of Statistical Software, 82, 1-26. https://doi.org/10.18637/jss.v082.i13

Latané, B., \& Darley, J. M. (1970). The unresponsive bystander: Why doesn't he help? New York: Appleton-CenturyCroft.

Lowry, P. B., Zhang, J., Wang, C., \& Siponen, M. (2016). Why do adults engage in cyberbullying on social media? An integration of online disinhibition and deindividuation effects with the social structure and social learning model. Information Systems Research, 27, 962-986. https://doi.org/10.1287/isre.2016.0671

Maas, C. J. M., \& Hox, J. J. (2005). Sufficient sample sizes for multilevel modeling. Methodology, 1, 86-92.

https://doi.org/10.1027/1614-2241.1.3.86

Machackova, H., Dedkova, L., \& Mezulanikova, K. (2015). Brief report: The bystander effect in cyberbullying incidents. Journal of Adolescence, 43, 96-99. https://doi.org/10.1016/j.adolescence.2015.05.010

McDonald, R. P. (1999). Test theory: A unified treatment. Mahwah, NJ: Erlbaum. Retrieved from http://site.ebrary.com/lib/alltitles/docDetail.action?doclD=10333567

McLean, C. P., \& Anderson, E. R. (2009). Brave men and timid women? A review of the gender differences in fear and anxiety. Clinical Psychology Review, 29, 496-505. https://doi.org/10.1016/j.cpr.2009.05.003

Modecki, K. L., Minchin, J., Harbaugh, A. G., Guerra, N. G., \& Runions, K. C. (2014). Bullying prevalence across contexts: a meta-analysis measuring cyber and traditional bullying. The Journal of Adolescent Health, 55, 602-611. https://doi.org/10.1016/j.jadohealth.2014.06.007

Nickerson, A. B., Aloe, A. M., Livingston, J. A., \& Feeley, T. H. (2014). Measurement of the bystander intervention model for bullying and sexual harassment. Journal of Adolescence, 37, 391-400.

https://doi.org/10.1016/j.adolescence.2014.03.003

Obermaier, M., Fawzi, N., \& Koch, T. (2016). Bystanding or standing by? How the number of bystanders affects the intention to intervene in cyberbullying. New Media \& Society, 18, 1491-1507.

https://doi.org/10.1177/1461444814563519

Obermann, M.-L. (2011). Moral disengagement among bystanders to school bullying. Journal of School Violence, 10, 239-257. https://doi.org/10.1080/15388220.2011.578276

Oh, I., \& Hazler, R. J. (2009). Contributions of personal and situational factors to bystanders' reactions to school bullying. School Psychology International, 30, 291-310. https://doi.org/10.1177/0143034309106499

O'Keeffe, G. S., \& Clarke-Pearson, K. (2011). The impact of social media on children, adolescents, and families. Pediatrics, 127, 800-804. https://doi.org/10.1542/peds.2011-0054 
Olenik-Shemesh, D., Heiman, T., \& Eden, S. (2015). Bystanders' behavior in cyberbullying episodes: Active and passive patterns in the context of personal-socio-emotional factors. Journal of Interpersonal Violence, 32, 23-48. https://doi.org/10.1177/0886260515585531

Olweus, D. (1993). Bullying at school: What we know and what we can do. Oxford: Blackwell.

Paciello, M., Fida, R., Tramontano, C., Lupinetti, C., \& Caprara, G. V. (2008). Stability and change of moral disengagement and its impact on aggression and violence in late adolescence. Child Development, 79, 1288-1309. https://doi.org/10.1111/j.1467-8624.2008.01189.x

Pfetsch, J. (2016). Who is who in cyberbullying? Conceptual and empirical perspectives on bystanders in cyberbullying. In M. F. Wright (Ed.), Bullying and victimization. A social-ecological approach to cyberbullying (pp. 121149). Hauppauge, New York: Nova Science Publishers, Inc.

Polanin, J. R., Espelage, D. L., \& Pigott, T. D. (2012). A meta-analysis of school-based bullying prevention programs' effects on bystander intervention behavior. School Psychology Review, 41, 47-65.

Pöyhönen, V., Juvonen, J., \& Salmivalli, C. (2012). Standing up for the victim, siding with the bully or standing by? Bystander responses in bullying situations. Social Development, 21, 722-741. https://doi.org/10.1111/j.14679507.2012.00662.x

Pozzoli, T., \& Gini, G. (2010). Active defending and passive bystanding behavior in bullying: The role of personal characteristics and perceived peer pressure. Journal of Abnormal Child Psychology, 38, 815-827.

https://doi.org/10.1007/s10802-010-9399-9

R Core Team. (2018). R: A language and environment for statistical computing. Vienna, Austria: R Foundation for Statistical Computing. Retrieved from https://www.R-project.org/

Rivers, I., Poteat, V. P., Noret, N., \& Ashurst, N. (2009). Observing bullying at school: The mental health implications of witness status. School Psychology Quarterly, 24, 211-223. https://doi.org/10.1037/a0018164

Rosseel, Y. (2012). lavaan: An R package for structural equation modeling. Journal of Statistical Software, 48, 1-36.

Runions, K. C., \& Bak, M. (2015). Online moral disengagement, cyberbullying, and cyber-aggression. Cyberpsychology, Behavior and Social Networking, 18, 400-405. https://doi.org/10.1089/cyber.2014.0670

Salmivalli, C., Lagerspetz, K., Björkqvist, K., Österman, K., \& Kaukiainen, A. (1996). Bullying as a group process: Participant roles and their relations to social status within the group. Aggressive Behavior, 22, 1-15. https://doi.org/10.1002/(SICI)1098-2337(1996)22:1<1::AID-AB1>3.0.CO;2-T

Salmivalli, C., Voeten, M., \& Poskiparta, E. (2011). Bystanders matter: Associations between reinforcing, defending, and the frequency of bullying behavior in classrooms. Journal of Clinical Child and Adolescent Psychology, 40, 668-676. https://doi.org/10.1080/15374416.2011.597090

Shultz, E., Heilman, R., \& Hart, K. J. (2014). Cyber-bullying: An exploration of bystander behavior and motivation. Cyberpsychology: Journal of Psychosocial Research on Cyberspace, 8(4), article 3. https://doi.org/10.5817/CP2014-4-3

Slee, P. T. (1994). Situational and interpersonal correlates of anxiety associated with peer victimisation. Child Psychiatry and Human Development, 25, 97-107. https://doi.org/10.1007/BF02253289

Slonje, R., \& Smith, P. K. (2008). Cyberbullying: Another main type of bullying? Scandinavian Journal of Psychology, 49, 147-154. https://doi.org/10.1111/j.1467-9450.2007.00611.x 
Smith, P. K., Cowie, H., Olafsson, R. F., \& Liefooghe, A. P. D. (2002). Definitions of bullying: A comparison of terms used, and age and gender differences, in a fourteen-country international comparison. Child Development, 73 , 1119-1133. https://doi.org/10.1111/1467-8624.00461

Suler, J. (2004). The online disinhibition effect. CyberPsychology \& Behavior, 7, 321-326.

https://doi.org/10.1089/1094931041291295

Thornberg, R., \& Jungert, T. (2013). Bystander behavior in bullying situations: basic moral sensitivity, moral disengagement and defender self-efficacy. Journal of Adolescence, 36, 475-483.

https://doi.org/10.1016/j.adolescence.2013.02.003

Thornberg, R., \& Jungert, T. (2014). School bullying and the mechanisms of moral disengagement. Aggressive Behavior, 40, 99-108. https://doi.org/10.1002/ab.21509

Thornberg, R., Wänström, L., Hong, J. S., \& Espelage, D. L. (2017). Classroom relationship qualities and socialcognitive correlates of defending and passive bystanding in school bullying in Sweden: A multilevel analysis. Journal of School Psychology, 63, 49-62. https://doi.org/10.1016/j.jsp.2017.03.002

van Cleemput, K., Vandebosch, H., \& Pabian, S. (2014). Personal characteristics and contextual factors that determine "helping," "joining in," and "doing nothing" when witnessing cyberbullying. Aggressive Behavior, 40, 383-396. https://doi.org/10.1002/ab.21534

van Noorden, T. H. J., Haselager, G. J. T., Cillessen, A. H. N., \& Bukowski, W. M. (2015). Empathy and involvement in bullying in children and adolescents: A systematic review. Journal of Youth and Adolescence, 44, 637-657. https://doi.org/10.1007/s10964-014-0135-6

Wachs, S. (2012). Moral disengagement and emotional and social difficulties in bullying and cyberbullying: Differences by participant role. Emotional and Behavioural Difficulties, 17, 347-360.

https://doi.org/10.1080/13632752.2012.704318 


\section{Appendix}

Table A1. Item Statistics and Factor Loadings of the Items of the SCARB (Social-Cognitive and Affective Reactions to Bullying).

$\begin{array}{ll} & \text { School Bullying } \\ \text { Item } & \text { When I notice someone being bullied at }\end{array}$

Cyberbullying

school...

When I notice someone being bullied

via digital media...

$\begin{array}{llllll}M & S D & \lambda & M & S D & \lambda\end{array}$

\section{Empathy}

... it affects me deeply.

... it hurts me, too.

... I realize how badly they are doing.

... I can well imagine how bad it must be

for them.

... I'm full of compassion.

... it makes me want to comfort them.
}

1.30

0.96

.72

1.24

0.95

.73

1.38

1.02

.81

1.36

1.01

.78

1.97

0.89

.63

1.98

0.94

1.89

0.92

.67

1.56

1.03

.61

1.96

0.99

.67

1.65

0.99

.80

1.56

1.01

.80

1.56

0.97

.73

\section{Moral Disengagement}

... I tell myself it's probably not that bad.

$\begin{array}{lll}0.65 & 0.72 & .54 \\ 0.82 & 0.77 & .41 \\ 1.23 & 0.96 & .46\end{array}$

... I know that it's really just fun.

.54

0.74

0.76

.50

... it's my opinion that there are worse

.41

0.78

0.79

things.

... I figure it's their own fault.

0.73

.67

1.27

0.97

0.75

0.77

0.82

0.73

.65

0.60

0.90

0.55

0.70

.59

1.23

0.81

1.33

0.89

.51

0.95

0.77

1.14

0.88

.56

0.68

.62

0.77

0.85

.70

with it on ther own.

... I believe that it's no concern of mine.

1.05

0.82

.58

1.07

0.83

.60

\section{Responsibility}

... I'm ashamed if I don't take actions

against it.

$\begin{array}{llllll}1.21 & 1.00 & .74 & 1.07 & 0.98 & .77 \\ 1.29 & 0.91 & .69 & 1.20 & 0.88 & .67 \\ 1.40 & 1.03 & .81 & 1.40 & 1.03 & .79 \\ & & & & & \\ 1.29 & 0.90 & .73 & 1.25 & 0.88 & .60 \\ 1.40 & 0.86 & .87 & 1.31 & 0.87 & .71 \\ 1.62 & 0.91 & .60 & 1.57 & 0.91 & .70\end{array}$

... I believe it's also my responsibility to do something against it.

... I feel guilty if I do nothing against it.

\section{Defender Self-Efficacy}

... I can immediately think of ways to do something against it.

... I have ideas how I can help them.

... I know that there are things I can do to improve the situation.

\section{Negative Outcome Expectations}

... I'm scared that I might be the next one if

\begin{tabular}{llllll}
1.02 & 1.07 & .81 & 1.00 & 1.08 & .79 \\
1.06 & 0.88 & .61 & 1.02 & 0.90 & .54 \\
0.94 & 0.98 & .67 & 0.83 & 0.91 & .57 \\
\hline
\end{tabular}

I say something against it.

... I'm afraid I will only make it worse if I try

to do something about it.

... I'm worried that the others won't like

me anymore if I take actions against it.

Note: The questionnaire was developed in German and all analyses are based on the German version. Two bilinguals translated and retranslated the items for this paper. Items were answered on a 4-point scale, ranging from never (0) to always (3). Due to missing values sample size for the item statistics varies between $n=479$ and $n=483$ for school bullying and between $n=477$ and $n=484$ for cyberbullying. Confirmatory factor analyses of the group-centered variables were conducted with $n=464$ and $n=454$ complete datasets for school bullying and cyberbullying respectively. $\lambda=$ fully standardized factor loadings. 
Table A2. Correlations of the Five Factors of the SCARB (Social-Cognitive and Affective Reactions to Bullying).

\begin{tabular}{|c|c|c|c|c|c|}
\hline & Empathy & MD & Responsibility & Self-Efficacy & NOE \\
\hline Empathy & - & $-.68 * \star \star$ & $.87 * \star \star$ & $.41 * \star \star$ & $.36 * \star \star$ \\
\hline MD & $-.75 * \star \star$ & - & $-.66 * \star \star$ & $-.31 * \star \star$ & $-.13 *$ \\
\hline Responsibility & $.81 * \star \star$ & $-.64 * \star \star$ & - & $.50 * \star \star$ & $.35^{\star \star \star}$ \\
\hline Self-Efficacy & $.62 * \star \star$ & $-.44 * \star \star$ & $.61 * * *$ & - & -.11 \\
\hline NOE & $.37 * * *$ & $-.14 *$ & $.35^{\star \star *}$ & .00 & - \\
\hline
\end{tabular}

Note: Correlations between the factors of the school bullying version of the SCARB are presented above the diagonal $(n=464)$, correlations between the factors of the cyberbullying version below $(n=454)$; MD = moral disengagement; $\mathrm{NOE}=$ negative outcome expectations.

${ }^{*} p<.05 .{ }^{* *} p<.01 . * * * p<.001$. 


\section{Correspondence to:}

Rhea-Katharina Knauf

Department of Educational Psychology and Health Psychology

Oberbettringer Straße 200

73525 Schwäbisch Gmünd

Germany

Email: rhea-katharina.knauf(at)ph-gmuend.de

Editorial record: First submission received on April 23, 2018. Revisions received on August 7, 2018, November 7, 2018, and November 19, 2018. Accepted for publication on November 15, 2018.

The article is part of the Special Issue "Bystanders of Online Aggression" guest edited by Hana Machackova (Masaryk University, Brno, Czechia), Jan Pfetsch (Technische Universität, Berlin, Germany), and Georges Steffgen (University of Luxembourg, Luxembourg).

\section{About Authors}

Rhea-Katharina Knauf, M. Sc., is engaged in research on the topic of bullying at the University of Education in Schwäbisch Gmünd. The aim of her doctoral thesis is to identify different roles in the context of cyberbullying as well as school bullying and characterize them regarding their social-cognitive and affective reactions to bullying.

Heike Eschenbeck is Professor of Psychology at the University of Education in Schwäbisch Gmünd. Her research focuses on the topics of well-being in schoolchildren, stress and coping as well as health behaviors in children and adolescents.

Michael Hock is Professor of Psychology at the University of Bamberg. His research interests include psychology of anxiety, emotion regulation and stress management, educational psychology and psychological assessment. 